\title{
Mental nerve neuropathy: case report and review
}

\author{
Amy Turner-Iannacci, DDS; ${ }^{*}$ Eisa Mozaffari, DMD; ${ }^{\dagger}$ Eric T. Stoopler, DMD
}

\begin{abstract}
Mental nerve neuropathy (MNN) or "numb chin syndrome" is a rare neurologic symptom most often associated with malignancy. Patients typically develop paresthesia or numbness localized to the chin and lower lip and will often seek care at their local emergency department. Pain and expansion of the lower jaw may also be present. We report a case of MNN associated with a metastatic lesion in the mandible. The purpose of this article is to highlight the importance of recognizing MNN, a potentially life-threatening symptom of metastatic carcinoma, and enable clinicians to properly diagnose MNN, which may mimic other conditions that affect the mandible.
\end{abstract}

Key words: mental nerve neuropathy, metastatic carcinoma

RÉSUMÉ

La neuropathie du nerf mentonnier est un symptôme neurologique rare le plus souvent associé aux tumeurs malignes. Les patients manifestent une paresthésie ou un engourdissement dans la région du menton et de la lèvre inférieure et rechercheront souvent des soins au département d'urgence local. On pourra noter également une douleur et une expansion de la mâchoire inférieure. Nous présentons un cas de neuropathie du nerf mentonnier associée à des lésions métastatiques au niveau de la maxillaire inférieure. Le présent article a comme objectif de souligner l'importance de l'identification de la neuropathie du nerf mentonnier, un symptôme potentiellement fatal du cancer métastatique et d'aider le clinicien à diagnostiquer avec exactitude ce type de neuropathie pouvant être confondu avec d'autres atteintes de la maxillaire inférieure.

\section{Introduction}

Mental nerve neuropathy (MNN) or "numb chin syndrome" is a clinical symptom of metastatic carcinoma to the mandible. MNN is defined as numbness or paresthesia localized to the chin or lower lip, and it is often accompanied by an abnormal sensation of "thickening" of the lip similar to the experience of dental anesthesia. Most cases that are not dental in origin are associated with diffuse metastatic disease, particularly with underlying lympho- proliferative disorders. ${ }^{1}$ The mandible is an uncommon site for metastatic carcinoma but when it is involved, the primary tumour commonly originates in the breast, lung, prostate, kidney, thyroid, ovaries or testicles. ${ }^{2}$ In $47 \%$ of cases, MNN precedes diagnosis of the primary tumour, ${ }^{3}$ and in patients with a history of cancer, MNN often indicates recurrence or progression of the disease. ${ }^{4}$ When MNN develops in patients with underlying carcinoma, survival is typically less than one year. ${ }^{5}$ We report the case of a patient who presented to a hospital emergency depart-

*Dr. Turner-lannacci is a Clinical Associate, tDr. Mozaffari is a Lecturer, and ¥Dr. Stoopler is an Assistant Professor, Department of Oral Medicine, University of Pennsylvania School of Dental Medicine, Philadelphia, Pa.

Received: Feb. 25, 2003; final submission: Apr. 15, 2003; accepted: Apr. 17, 2003

This article has been peer reviewed.

Can J Emerg Med 2003;5(4):259-62 
ment (ED) for evaluation of mandibular swelling and a numb chin. Emergency physicians should be aware of this disorder because patients with MNN often seek initial evaluation at their local ED.

\section{Case report}

A 61-year-old woman presented to the ED complaining of swelling in her jaw and numbness of her right lower lip. The swelling had appeared 3 weeks earlier and slowly increased. Two days before her ED visit, the patient noticed numbness and tingling in her right lower lip adjacent to the premolar teeth. Her past medical history was significant for hypertension and adenocarcinoma, but the latter was successfully treated, and the patient had been in remission for 4 years. She was otherwise well and on no medications. After examining her, the ED house staff diagnosed a dental infection and initiated antibiotics, but because of the unusual clinical presentation, the attending emergency physician consulted the Oral and Maxillofacial Surgery service.

A detailed examination revealed facial asymmetry, with fullness over the right mandible. Multiple lymph nodes were palpable in the right submandibular and cervical chain, with several of these being firm, fixed and greater than $1 \mathrm{~cm}$ in size. Cranial nerves were intact, apart from a $1-\mathrm{cm}$ area on the right lower lip that was anesthetic to touch and pin prick. The anesthetic area included the labial mucosa, vermillion border and extra-oral skin adjacent to the premolar teeth. Oral examination revealed poor dentition. The right posterior mandible was devoid of teeth, and

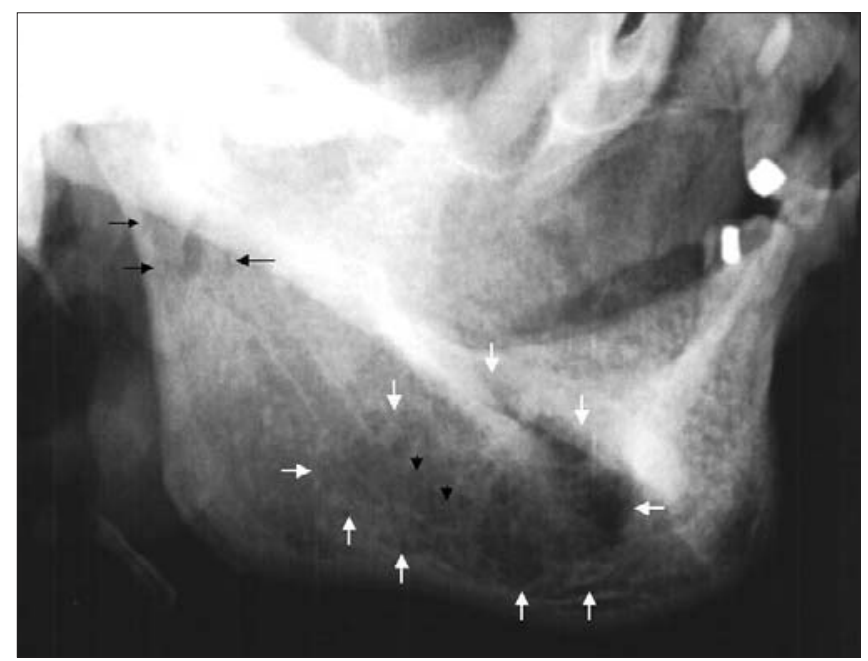

Fig. 1. Lateral oblique view of the mandible demonstrating an ill-defined radiolucent area in right mandibular body. The small white arrows demonstrate extension of the tumour. Black arrows show radiolucent areas in the right neck and head of the condyle of the right temporomandibular joint. a palpable expansile bony swelling had displaced the buccal and lingual cortical plates.

X-rays revealed a $1.5-\mathrm{cm}$ circumscribed lytic lesion in the body of the right mandible and a smaller lesion in the neck of the mandibular condyle (Fig. 1). Computed tomography (CT) images suggested that these lesions were most consistent with metastatic carcinoma (Figs. 2 and 3). Further studies confirmed metastatic carcinoma of the mandible with involvement of the liver. The patient was admitted to the Oncology service for ongoing care.

\section{Discussion}

MNN is a symptom caused by dysfunction of the terminal sensory branch of the mandibular division of the trigeminal nerve. ${ }^{6} \mathrm{MNN}$ is commonly due to compression of the mental or inferior alveolar nerve from a lesion present in the mandible or skull. ${ }^{5}$ Initially, the altered sensation is unilateral, but this may progress and cause bilateral mandibu-

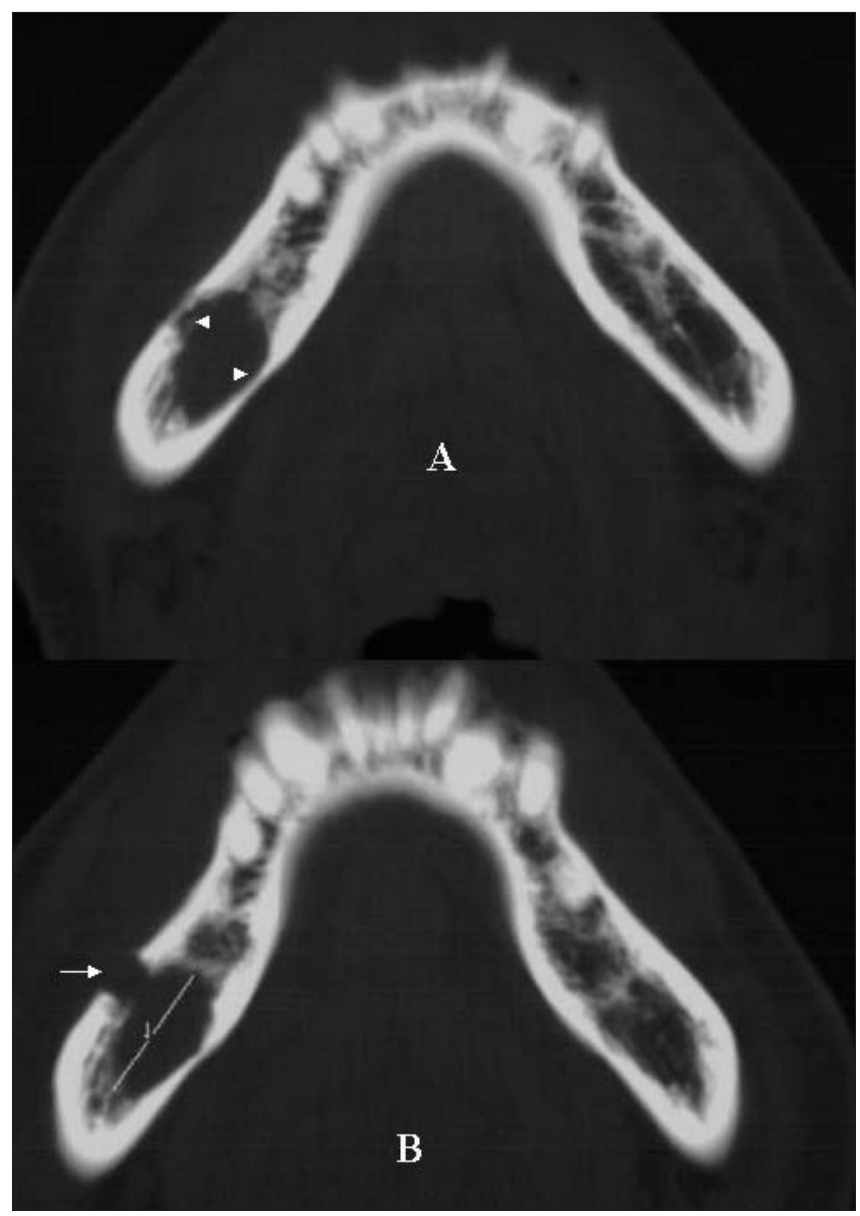

Fig. 2. Axial computed tomography (bone window) demonstrates cross sectional view of the mandibular body. The arrow denotes perforation of the buccal cortical plate, and the arrowheads denote erosion of the lingual cortical plate. 
lar symptoms. ${ }^{4}$ Glaser and colleagues ${ }^{2}$ described anesthesia and pain as the main symptoms of metastatic mandibular disease, and patients generally report paresthesia or dysesthesia in the peripheral distribution of the inferior alveolar and mental nerves. This symptom is the most consistent finding when a neoplasm is located in the ramus and body of the mandible, ${ }^{2}$ as was the case with our patient. The pain associated with a metastatic mandibular lesion can be severe and intense, and it may mimic a toothache, temporomandibular joint discomfort, osteomyelitis or atypical trigeminal neuralgia. ${ }^{2}$

MNN may also be associated with local trauma, cysts, inflammatory disorders, mandibular atrophy or iatrogenic nerve injury by dental anesthesia.? Other systemic causes of MNN include neurological disorders, diabetes mellitus, sarcoidosis, amyloidosis and sickle cell anemia (see Table 1) ${ }^{5.8}$ The literature review by Laurencet and coworkers $^{5}$ suggests that lymphoma and adenocarcinoma of the breast are the primary tumours most likely to metastasize to the mandible. In patients with suggestive symptoms, mandibular $\mathrm{x}$-rays or panoramic films may be diagnostic.

\begin{tabular}{ll}
$\begin{array}{l}\text { Table 1. Possible etiologies of mental nerve } \\
\text { neuropathy }\end{array}$ \\
\begin{tabular}{ll} 
Local factors & \multicolumn{1}{c}{ Systemic factors } \\
\hline Dental disease & Metastatic carcinoma \\
Cysts & Neurological disorders \\
Trauma & Diabetes \\
Mandibular atrophy & Sarcoidosis \\
Temporomandibular disorder & Amyloidosis \\
latrogenic & Sickle cell anemia \\
\hline
\end{tabular} \\
\hline
\end{tabular}

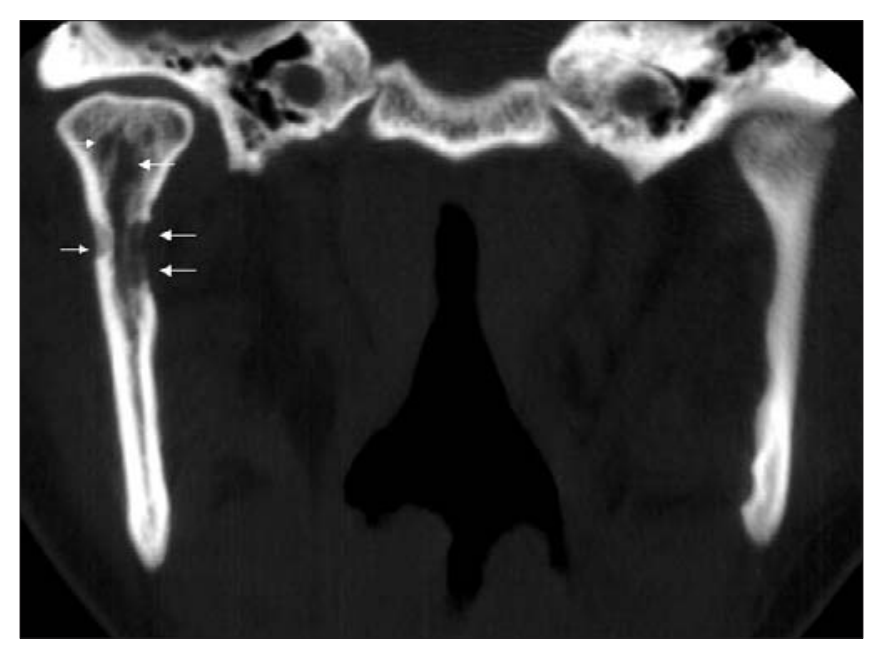

Fig. 3. Coronal CT view (bone window) of temporomandibular joint area. Notice the resorption of the medial and lateral aspects of the right condylar neck and enlargement of marrow spaces and bone resorption on the condylar head (arrows).
A standard mandible series includes a right and left lateral oblique, posterior-anterior (PA) view, reverse Towne's and submental vertex radiographs. The panoramic view is a valuable screening method because it has tomographic effects and visualizes the entire mandible, both temporal-mandibular joints, and maxillary sinuses on one film, allowing for more reliable comparison of anatomic structures. In patients with a history of carcinoma, radiographic evaluation should include a CT scan of the mandible, basal skull, head and neck if possible. ${ }^{5} \mathrm{CT}$ provides images of thin sections of both hard and soft tissues without superimposition.

If no traumatic etiology or systemic disease is apparent, physicians should look for dental disease. Odontogenic infections and abscesses can present as intra-oral or facial swelling, which may be firm or fluctuant, with or without discharge, erythema and heat. Patients will often complain of spontaneous and increasing pain that is aggravated by heat, cold or chewing. Clinical exam may reveal tooth decay, dental restorations or both in the affected tooth. Periodontal infections may present with similar symptoms. In such cases, the gingiva may appear erythematous and edematous with deposits of plaque (white, thin) or calculus (yellow to brown or black) around the necks of the teeth.

Patients with temporomandibular joint dysfunction or myofascial pain syndromes often present with intermittent or constant dull pain that may be associated with mastication (e.g., temporalis or masseter use). In these cases, cheek, temporal and periauricular pain are common, and patients may report a history of grinding, clenching and reduced jaw excursion. Patients may also have experienced their jaw "locking" open or closed in the past.

Trigeminal neuralgia is characterized by sharp, often excruciating pain that is stimulated by a trigger; the patient often identifies the specific area and action that stimulates their discomfort.

\section{Conclusion}

MNN is most frequently associated with primary, progressive and metastatic carcinoma involving the mandible. Physicians should be aware of the relevant symptoms, consider both local and systemic causes, and avoid misdiagnosing this condition as a simple dental infection.

Competing interests: None declared.

\section{References}

1. Halachmi S, Madeb R, Madjar S, Wald M, River Y, Nativ O. Numb chin syndrome as the presenting symptom of metastatic prostate carcinoma [abstract]. Urology 2000;55:286.

2. Glaser C, Lang S, Pruckmayer M, Millesi W, Rasse M, Marosi 
$\mathrm{C}$, et al. Clinical manifestations and diagnostic approach to metastatic cancer of the mandible. Int J Oral Maxillofac Surg 1997;26:365-8.

3. Massey EW, Moore J, Schold SC. Mental neuropathy from systemic cancer. Neurology 1981;31:1277-81.

4. Lossos A, Siegal T. Numb chin syndrome in cancer patients: etiology, response to treatment, and prognostic significance. Neurology 1992;42:1181-4.

5. Laurencet FM, Anchisi S, Tullen E, Dietrich PY. Mental neuropathy: report of five cases and review of the literature. Crit Rev Oncol Hematol 2000;34:71-9.

6. Burt RK, Sharfman WH, Karp BI, Wilson WH. Mental neuropathy (Numb Chin Syndrome). A harbinger of tumour progression or relapse. Cancer 1992;70:877-81.
7. Hiraki A, Nakamura S, Abe K, Takenoshita Y, Horinuchi Y, Shinohara M, Shirasuna K. Numb chin syndrome as an initial symptom of acute lymphocytic leukemia: report of 3 cases. Oral Surg Oral Med Oral Path Oral Radiol Endod 1997;83:555-61.

8. Silverstein LH, Szikman M, Melkonian R, Dubovsky D. Mental neuropathy associated with malignant disease: a case report. J Oral Implantol 1994;20:63-4.

Correspondence to: Dr. Eric T. Stoopler, Department of Oral Medicine, University of Pennsylvania School of Dental Medicine, 240 South 40th St., Philadelphia PA 19104 USA; 215 746-0112, fax 215 573-7853, ets@pobox.upenn.edu 